\title{
BURJ KHALIFA - CONSTRUCTION AND QUALITY CONTROL
}

\author{
D.S. Rajendra Prasad \\ ${ }^{1}$ Sr. QA/QC Projects Manager, Azmeel Contracting Company, Kingdom of Saudi Arabia
}

\begin{abstract}
This paper presents a snapshot of Construction and Quality Control system adopted during the construction of World's Tallest Tower, "The BurjKhalifa Tower", Dubai, UAE. An effective, well-constructed and well-maintained building is essential for safety and durability of any structure. In order to achieve this, the safety and quality aspects should be built-in during the design and construction stage rather than at the inspection stage. The construction practices adopted at BurjKalifa Tower is simply "Do the right thing, right, first time, every time” by following established approved Project Quality Plan (PQP) and Inspection Test Plans (ITPs) with well narrated method statements and definite objective checklists/formats. Project Management Information System (PMIS) was effectively and efficiently used in day-to-day construction activities for ensuring: an advanced information on construction activity (what, when, where, who, how, with what), with well repository of documents, good track on resources, providing precise information to subcontractors and keep a tab on commercials. DOKA Auto-climbing formwork was used for the Tower cores and HunnebeckTable formwork for the Podium slabs and FRP shuttering for walls of circular Car parking ramps. Aluminum shuttering (MevaDec panel formwork) was adopted for tower slabs. C80 grade concrete was used in tower columns and shear walls and C50 grade concrete for beams and slabs. Podium rafts was casted with C50 grade concrete. Tower walls constructed adopting 3-day cycle for each level and reinforcement bars were fabricated for the height of 2 levels with couplers for the laps for beams and slabs and for nose columns. De-shuttering of tower walls after 10hours of pull-out tests complying with a minimum strength of 10MPa. Composite link beams were used to connect core walls and nose columns. This multi-purpose, ultrahigh, skyscraper was successfully completed in a record time by the joint venture of Samsung, BeSix and ArabTec sponsored by Emaar Properties.
\end{abstract}

Keywords: BurjKhalifa Tower, Quality, Construction, Formwork, Concrete. $* * *$

\section{INTRODUCTION}

The BurjKhalifa Tower is a multi-purpose, ultra-high, skyscraper was successfully completed in a record time by the joint venture of Samsung, BeSix and ArabTec sponsored by Emaar Properties. The tower has a total area of 479,830

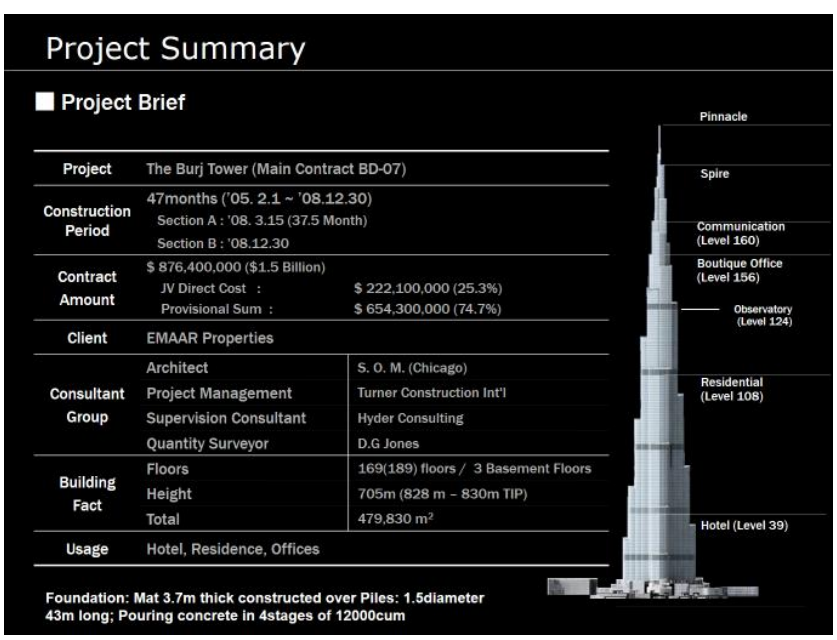

Fig- 1a: Snapshot of Project Summary - Burj Development, Project Brief $\mathrm{m}^{2}$ that includes hotel, residential, commercial, shopping, entertainment, observatory, communication and parking facilities[10]. The figure 1 is a snapshot of the project summary.

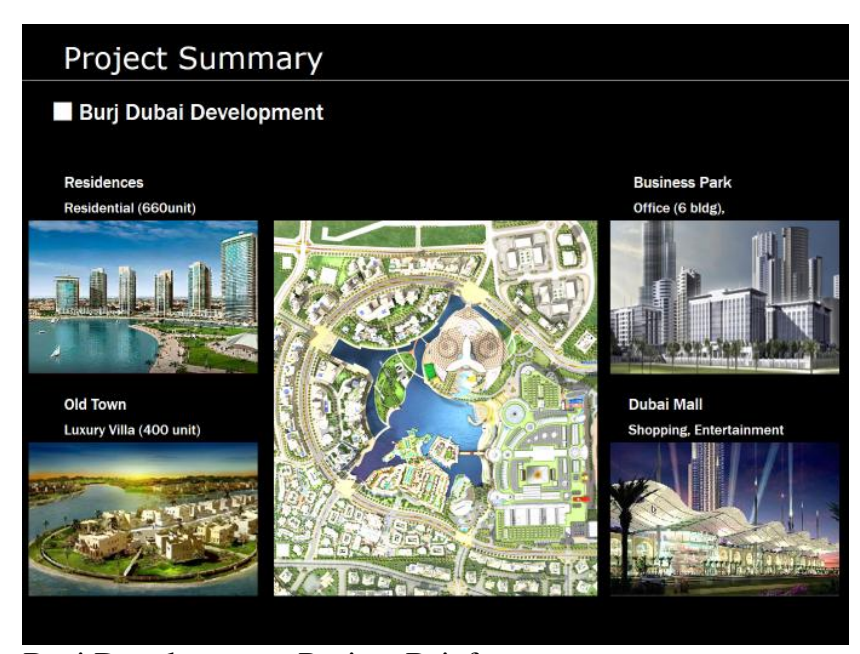

Project Summary 

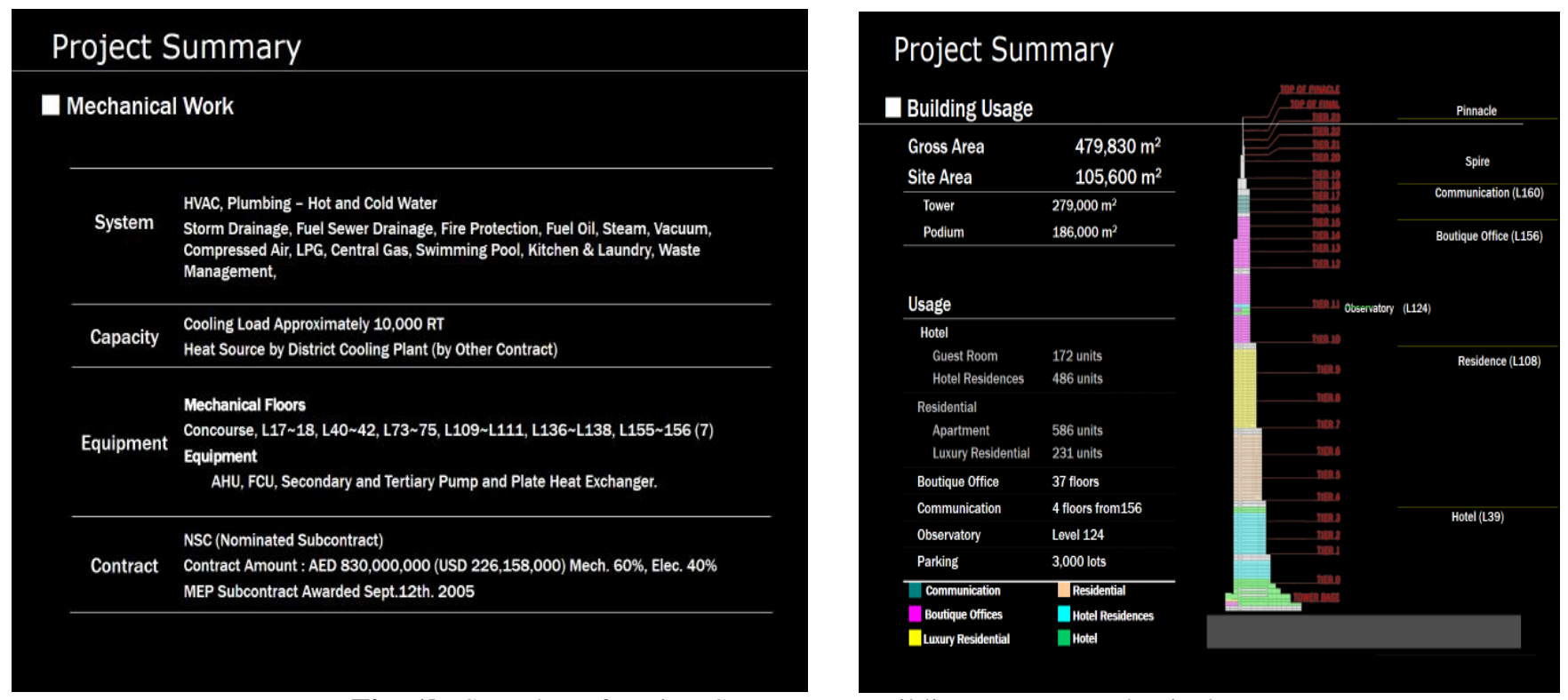

Fig- 1b: Snapshot of Project Summary - Building Usage, Mechanical
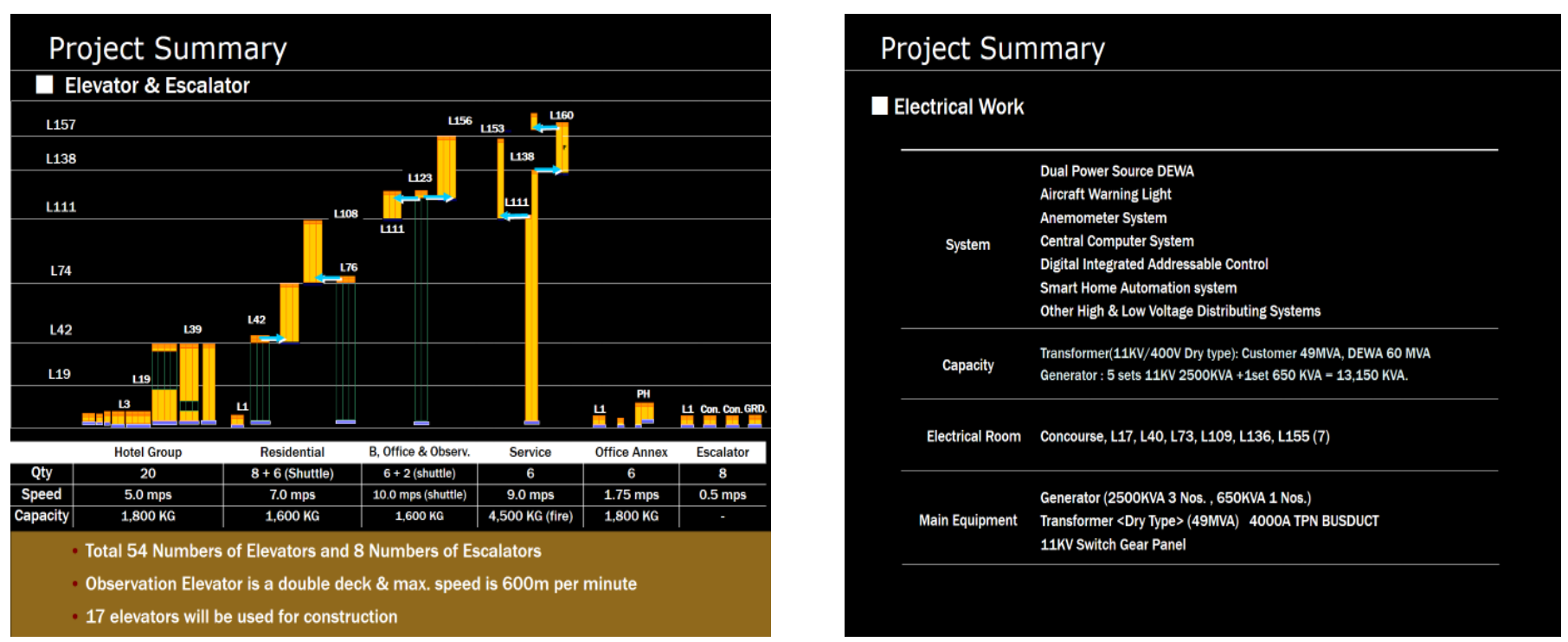

Fig- 1c: Snapshot of Project Summary - Electrical, Elevator \& Escalator

\subsection{Design Overview}

The architectural design concept was derived from Blue Dick, the flower of the desert[8].

- The plan is reducing in a spiral pattern, symbolizing the Dubai economy.

- Seek the model of Future city for Middle East By the beauty of shape \& scale

An effective, well-constructed and well-maintained building is essential for safety and durability of any structure. The tower has adopted the most stabilized Y-Shape, which provides stability by building weight shifts to end of the wings and structure considering both stability, constructability[9]. 


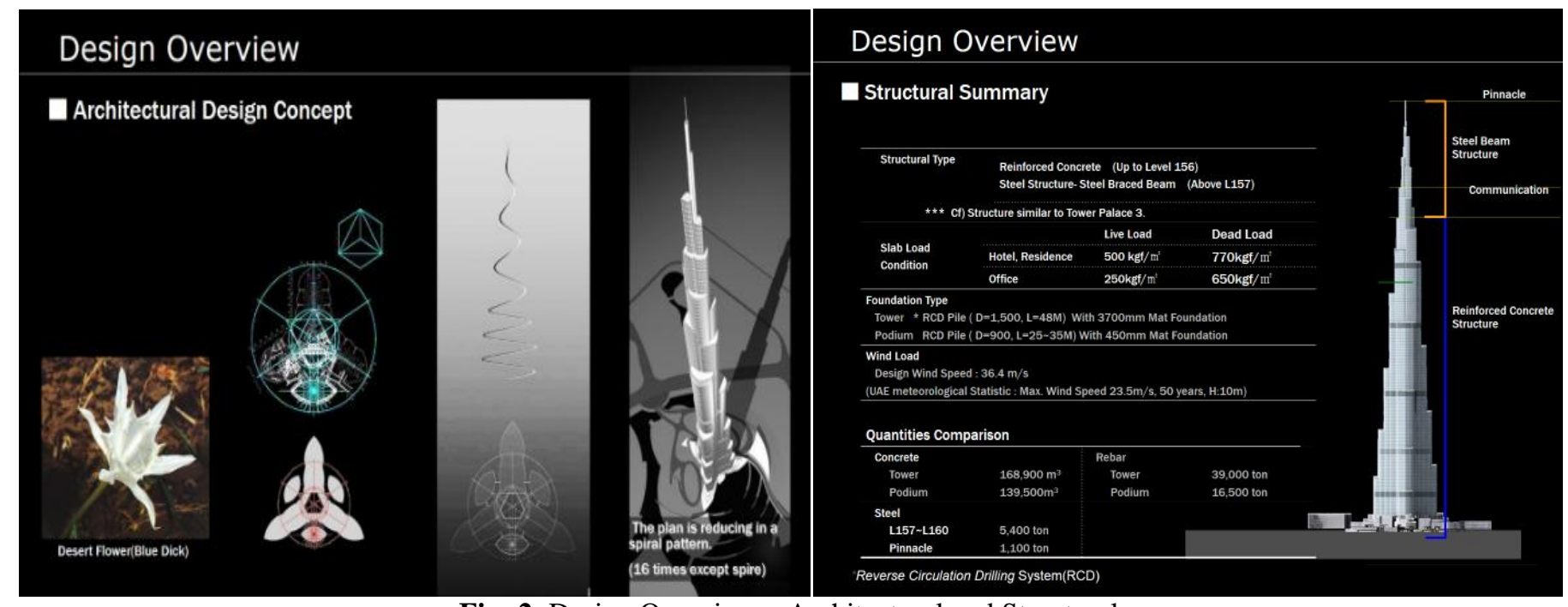

Fig- 2: Design Overview - Architectural and Structural
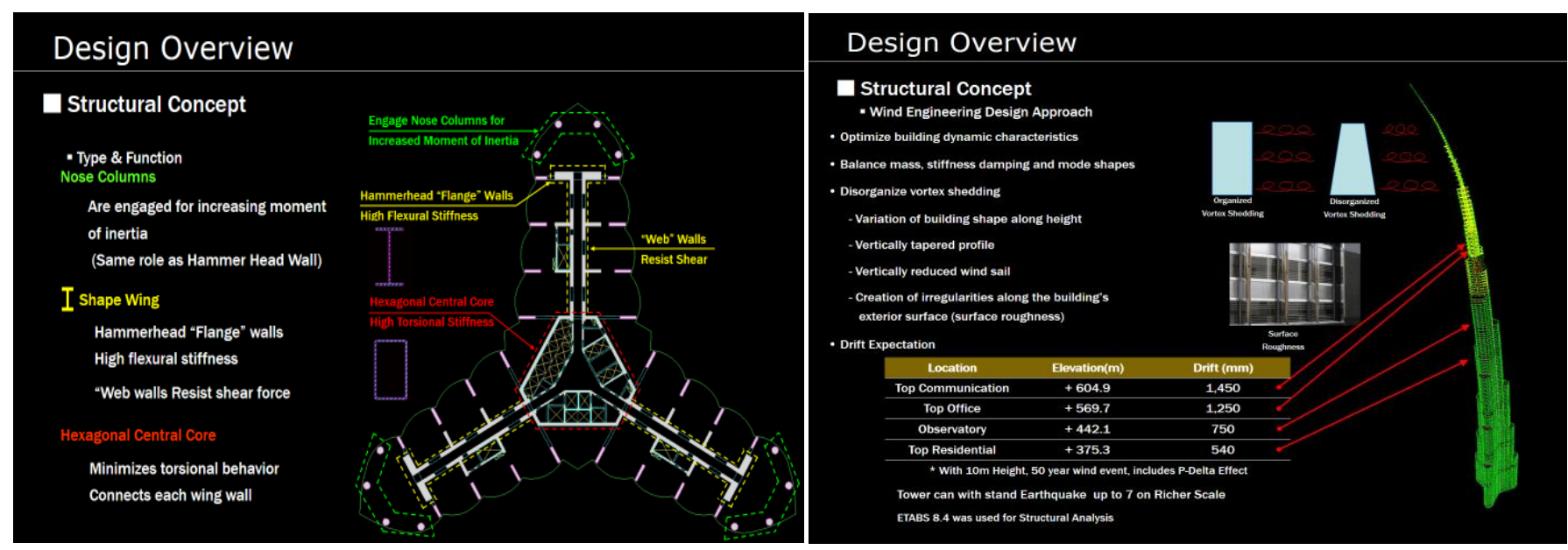

Fig- 3: Design Overview - Structural

Emergency evacuation is given prime importance during design development stage. The construction practices adopted at BurjKalifa Tower is simply "Do the right thing, right, first time, every time" by following established approved Project Quality Plan (PQP) and Inspection Test Plans (ITPs) with well narrated method statements and definite objective checklists/formats[3]. Project
Management Information System (PMIS) was effectively and efficiently used in day-to-day construction activities[2]. JV Operation Processed by Computer System and allows Information Real Time Update (Manager Group of JV Informed Instantly) and Ubiquitous Access (Site - EMO Headquarter) to all stakeholders.
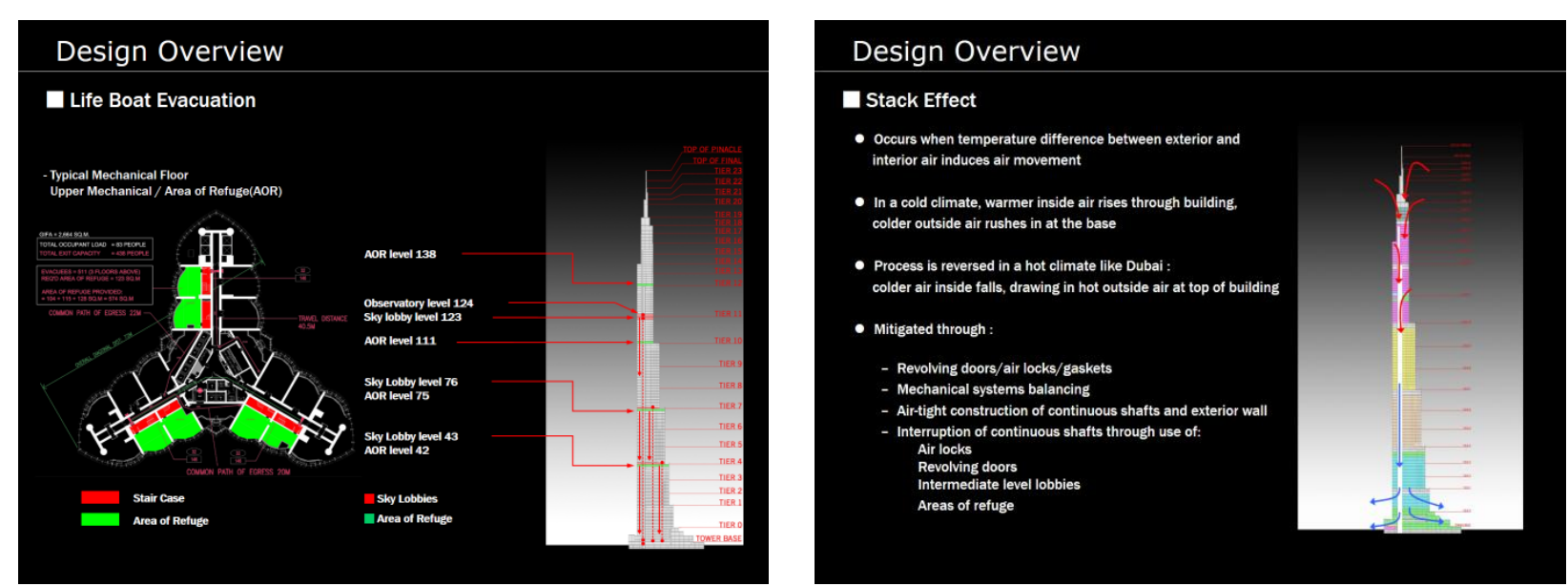

Fig- 4: Life boat evacuation and Stack effect 


\section{PROJECT QUALITY PLAN}

Samsung JV considers the Project Quality Planning is a crucial step and it should be done well before construction work is due to commence[3,4]. It is amalgamated with the traditional project planning in such activities as nomination of subcontractors and suppliers, determination of construction methods, construction programming, logistics plan, site layout, identification of manpower requirements and training needs, material and plant acquisition, etc. The following diagram depicts the development of the Project Quality Plan.
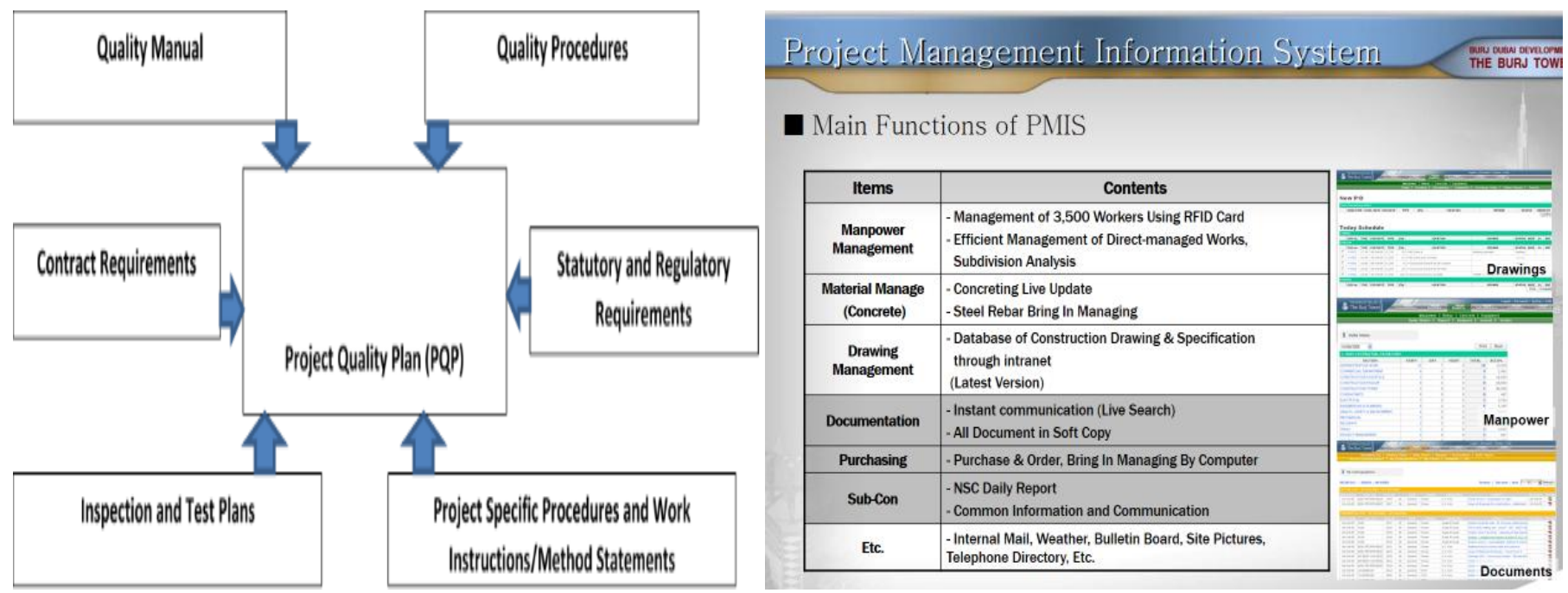

Fig-5: Project Quality Plan development and PMIS

\subsection{Logistics Plan}

The tower was located in the middle of Burj Dubai Development Site and there are favorable Access \& Security (Air, Water, Road, Rail), mutual interface with other Burj Dubai project (Dubai Mall \& Lake, Development Plan). The construction access is a crucial factor for safe and timely transport of material, equipment and manpower.

- Tower Section is enclosed by Podium
- Tower Section works, like stocking, lifting \& concrete pumping, occur at the same time with Podium Works.

- Comparatively long distance from gate to Tower and disrupted by Podium construction.

It is necessary to provide sufficient well planned Stock Yards for the storage of material for project and limited Stock area for Tower Section. The tower site area is about $105,600 \mathrm{~m}^{2}$ and which includes the tower and podium. The podium is dived into zone $-\mathrm{A}$ Office Annex, Zone-B the Pool Annex and Zone-C the parking areas.
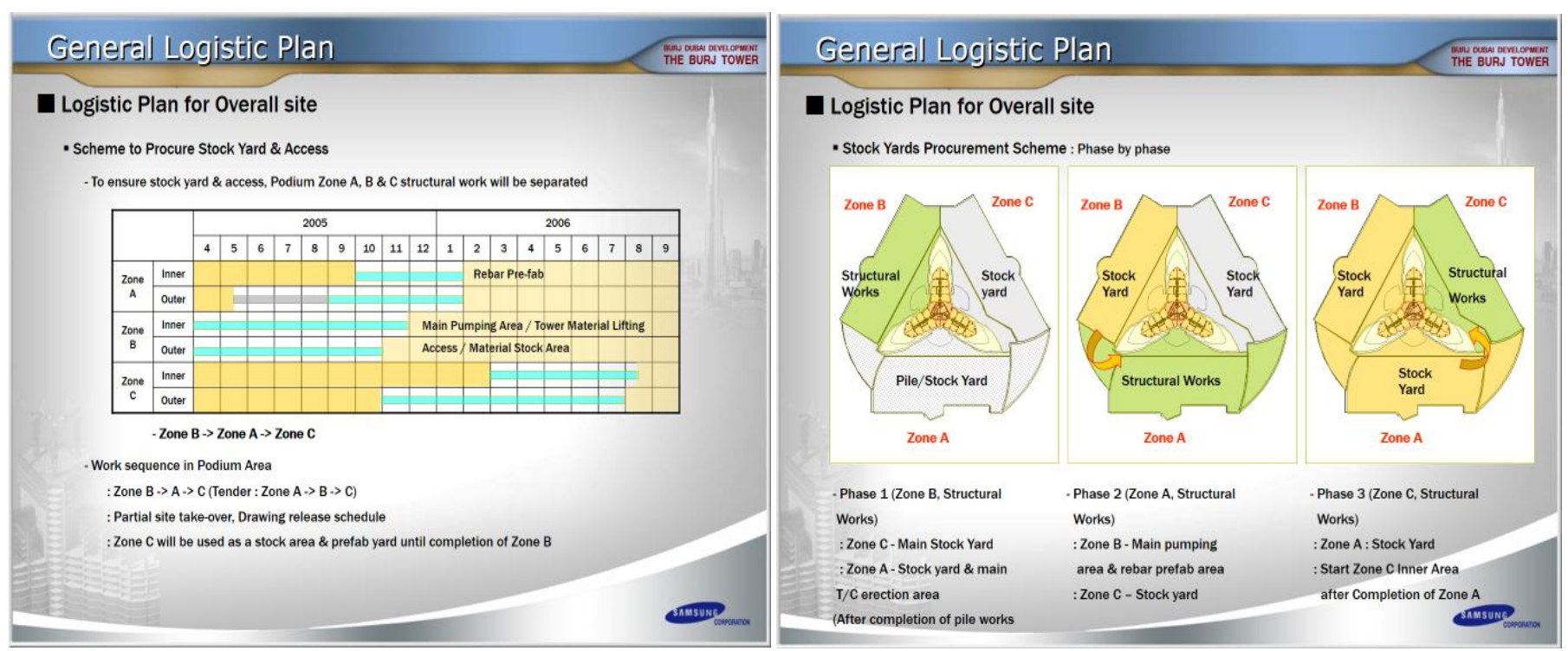

Fig- 6: Logistics Plan for Overall site 

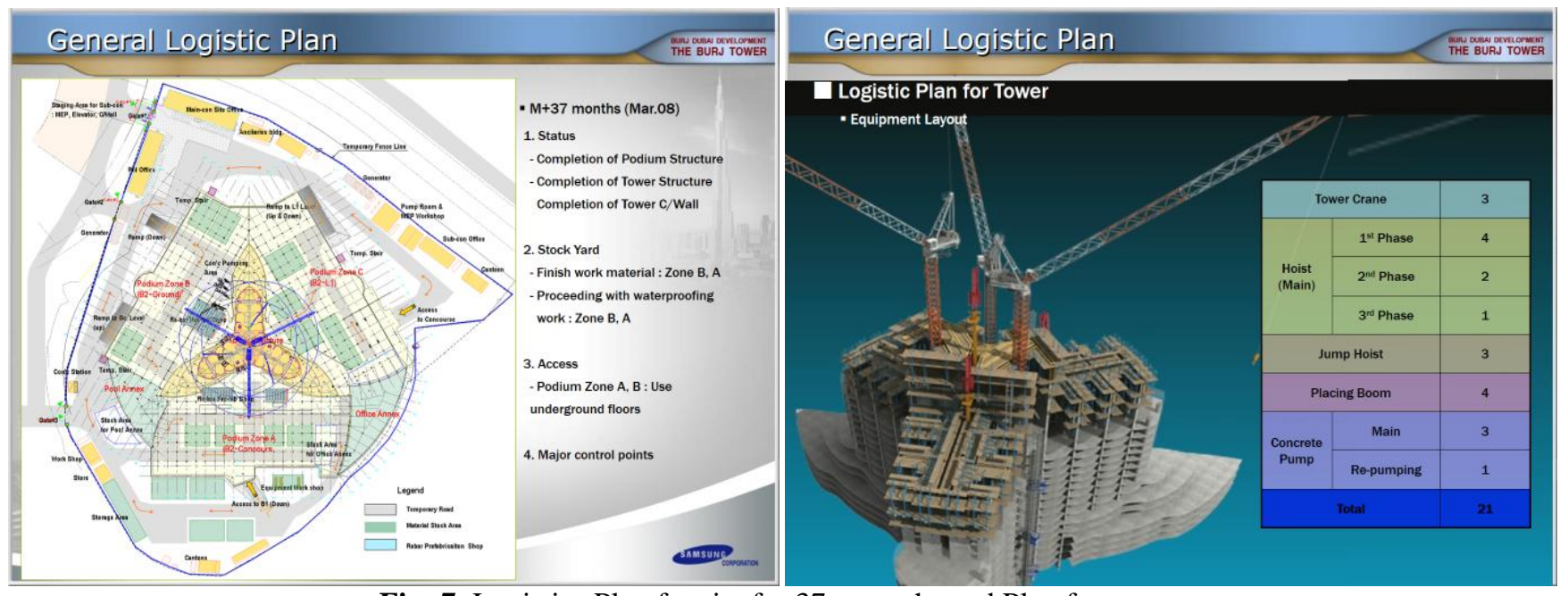

Fig- 7: Logistics Plan for site for 37+ months and Plan for tower

\subsection{Quality Control and Safety Plan}

Quality Policy Statement is to ensure a totally Customer driven approach that meets and exceeds customer expectations through effective management and performance, good co-ordination increased productivity and greater focus on business objectives.

Quality Control Procedures will be developed in line with the project specification, ITP, approved relevant documents, submittals and approved method statements. All the procedures will be developed and submitted formally to the consultant for approval and accordingly distributed to all concerned.

Repairs and Retrofitting if any should be carried with approved method statements and with approved materials[1, 5]

BurjKhalifa safety program has been developed considering 4 phases as illustrated below.
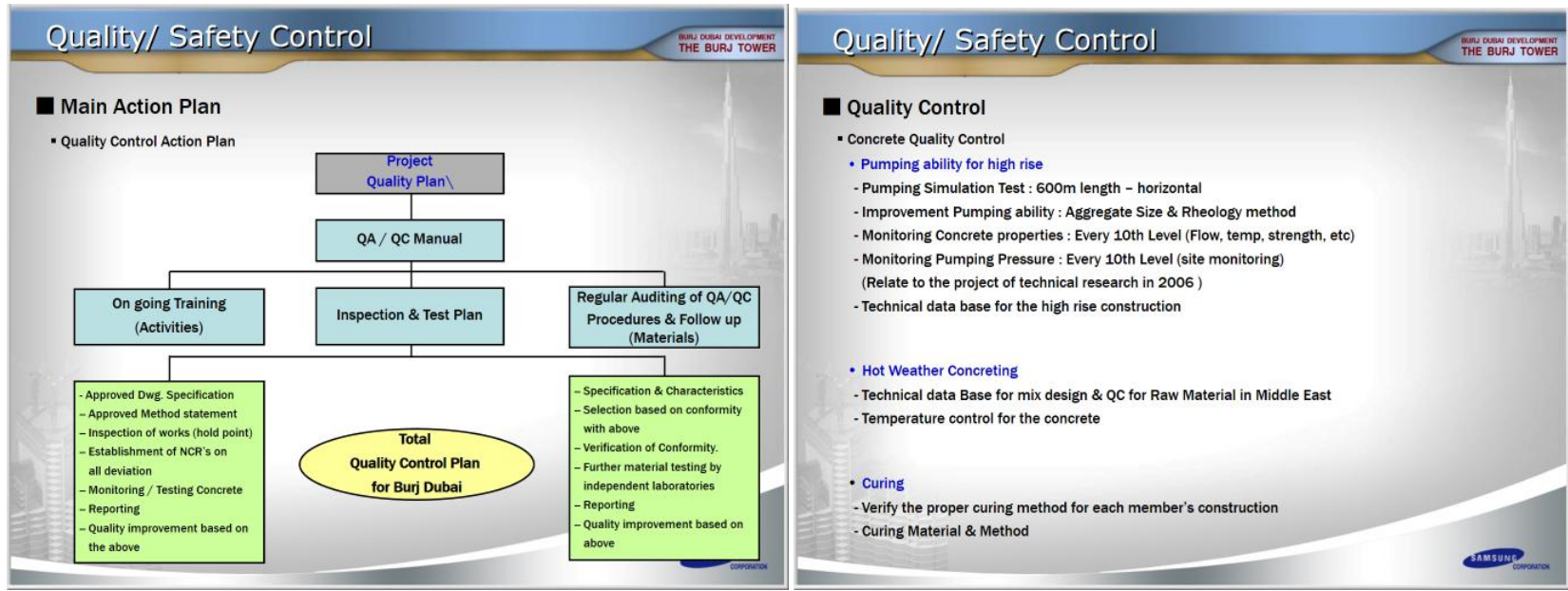

Fig- 8: Quality Control action Plan 

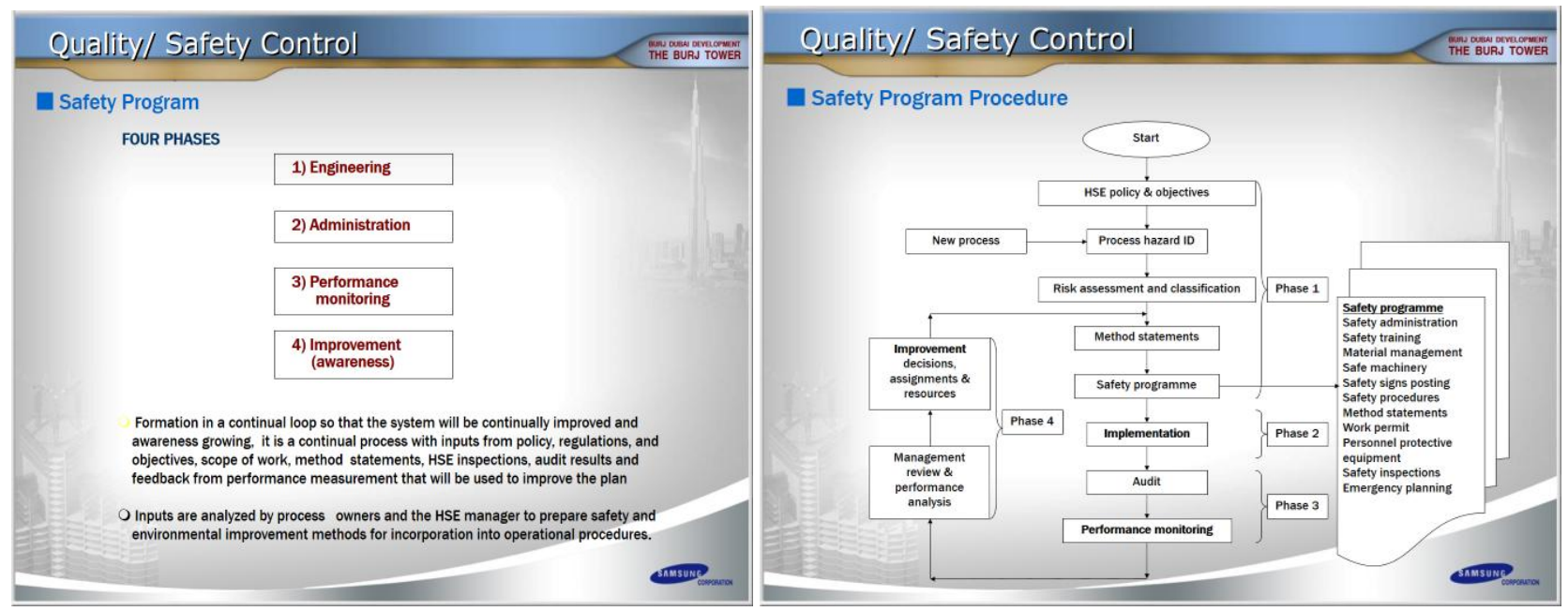

Fig- 9: Safety Control Program and procedure
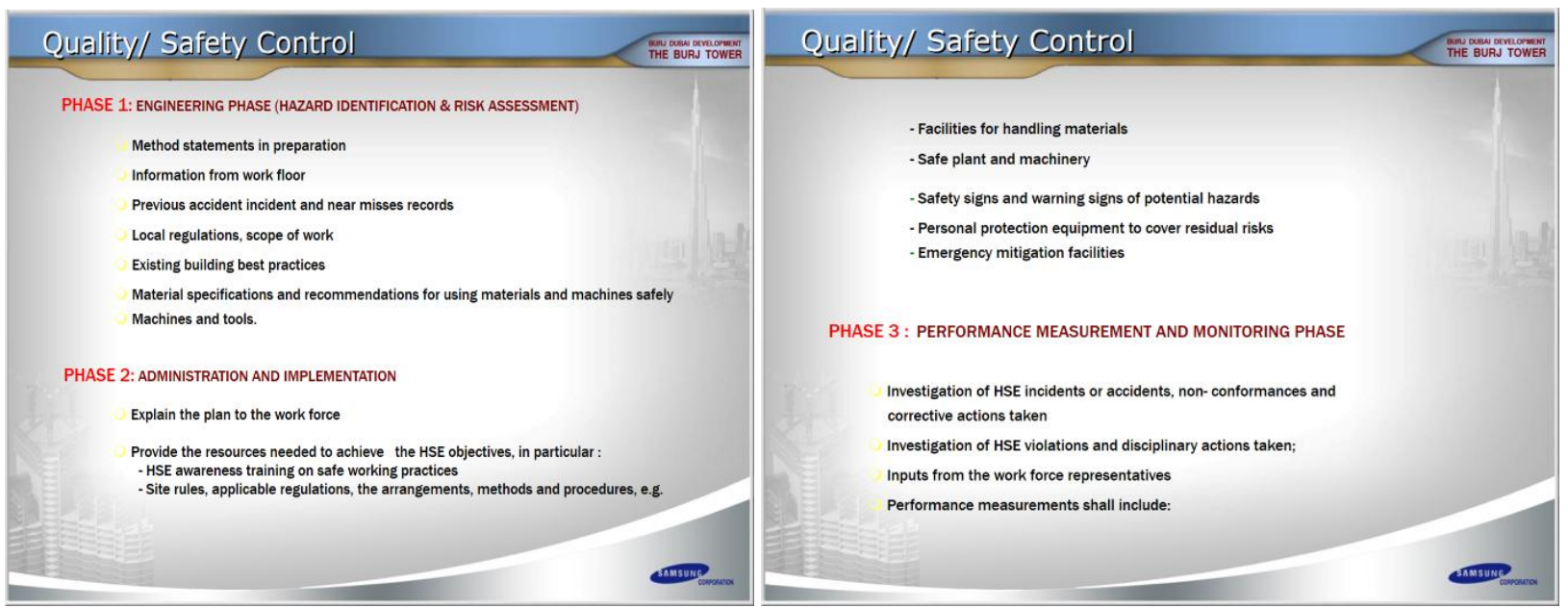

Fig- 10: Safety Control Program and procedure

\subsection{Construction Equipment and Plan}

The three tower crane were installed in tower Cores 1,2 and 3 :

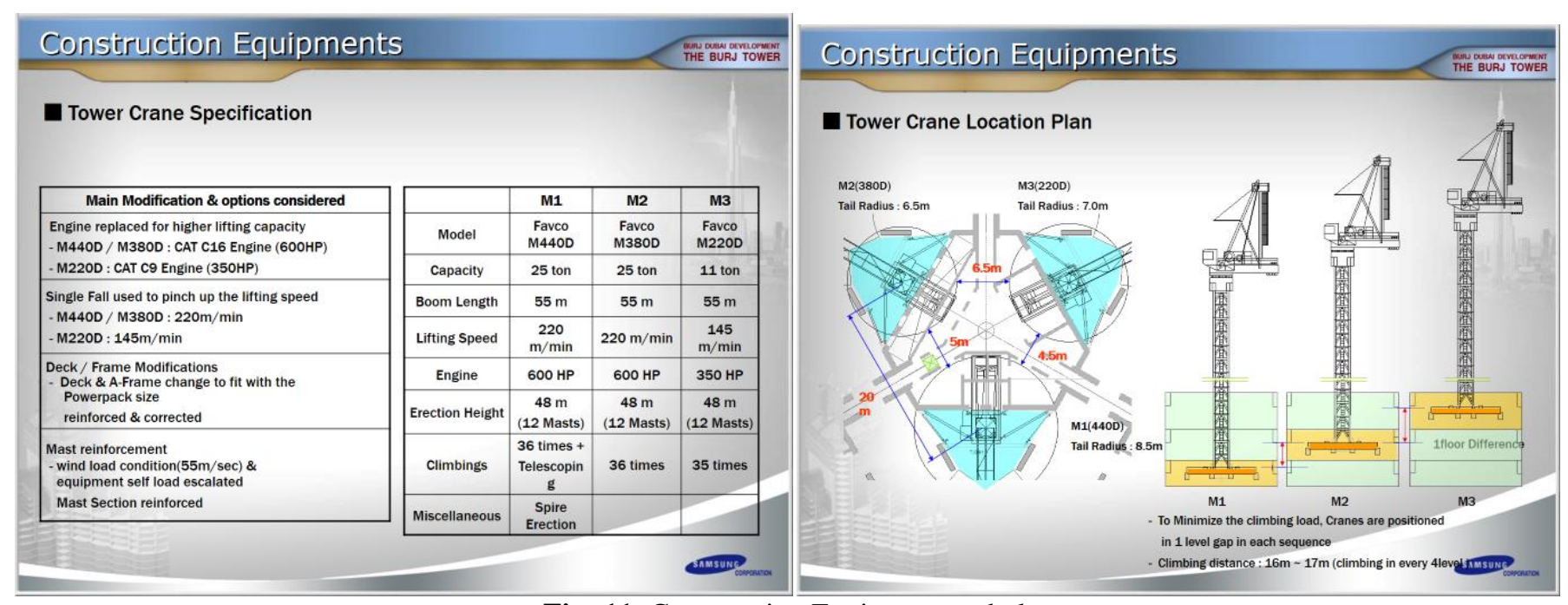

Fig- 11: Construction Equipment and plan 


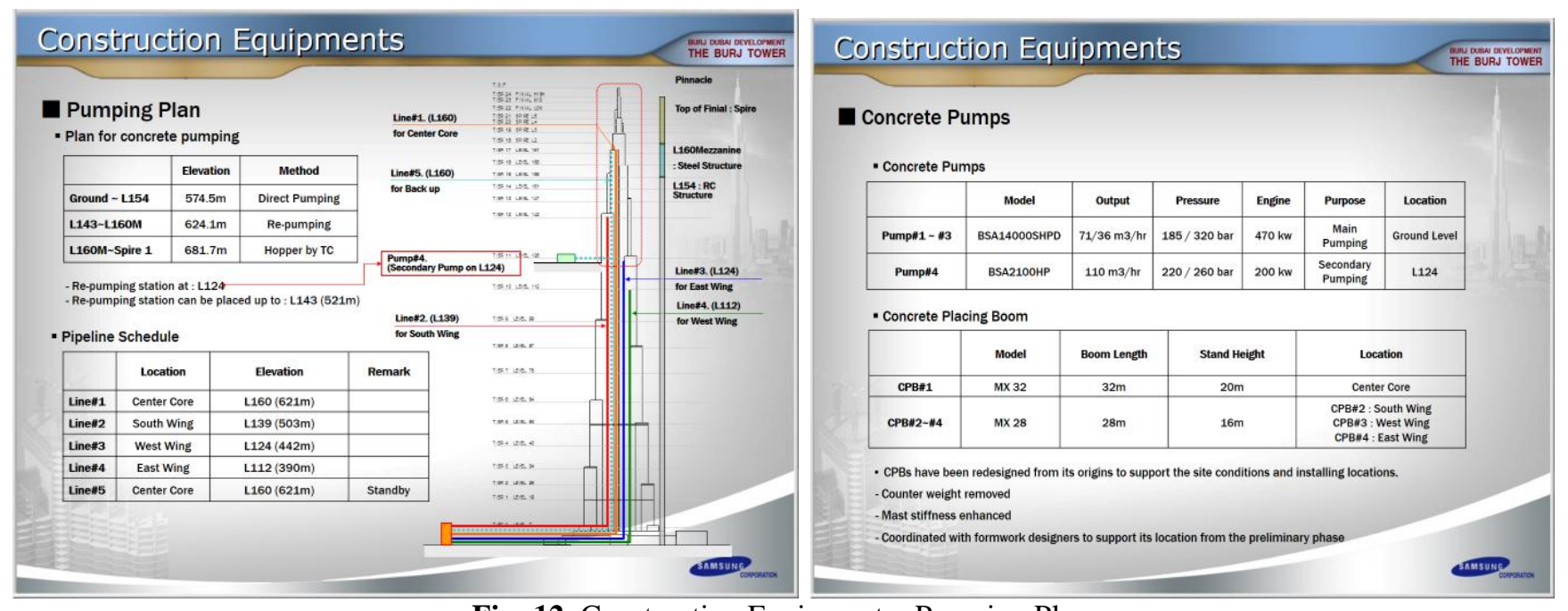

Fig- 12: Construction Equipment - Pumping Plan

3-day Cycle for walls and slabs have been adopted and sequencing of pouring concrete is shown below.
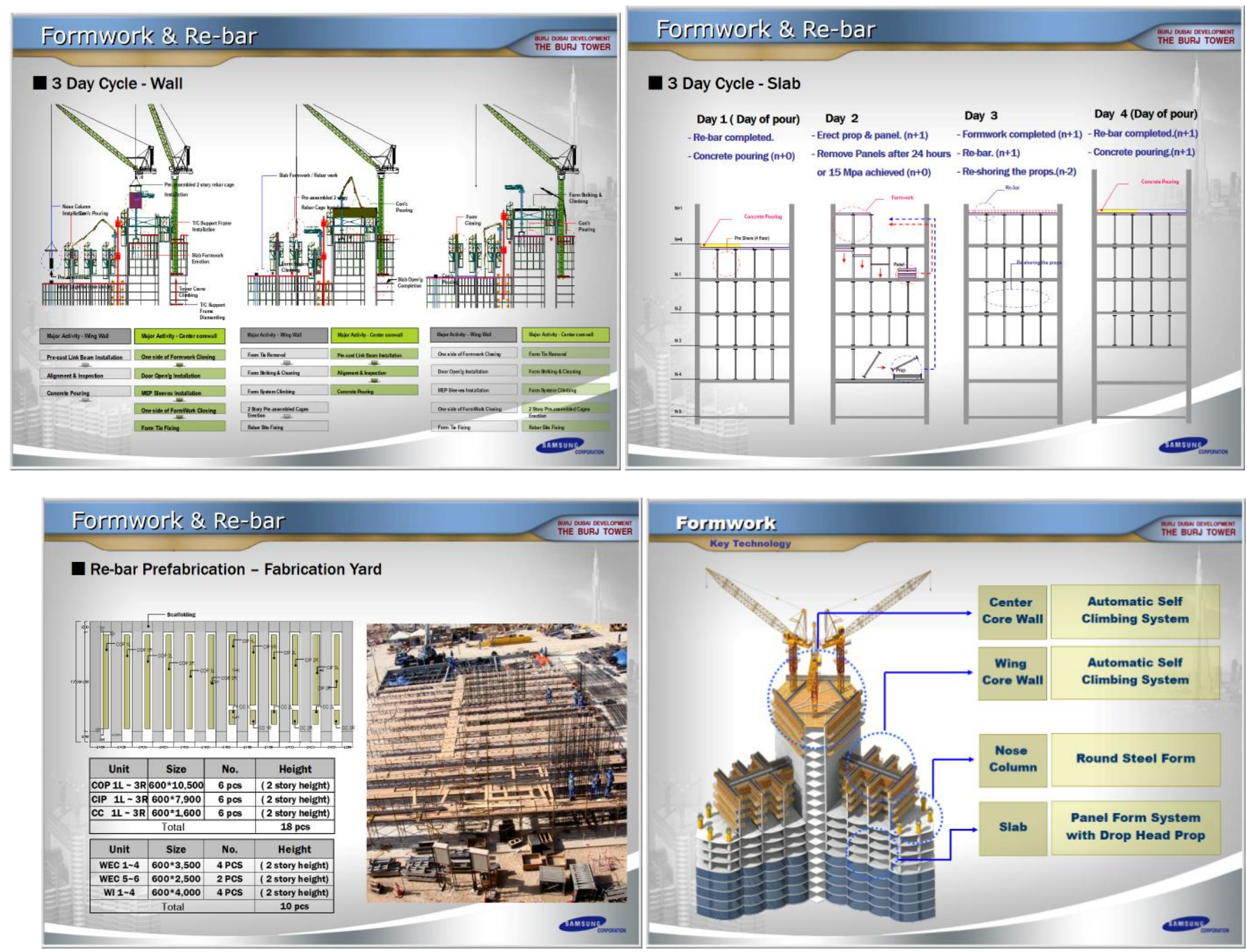

Fig-13: 3 day Cycle for Formwork and Rebar fabrication yard 

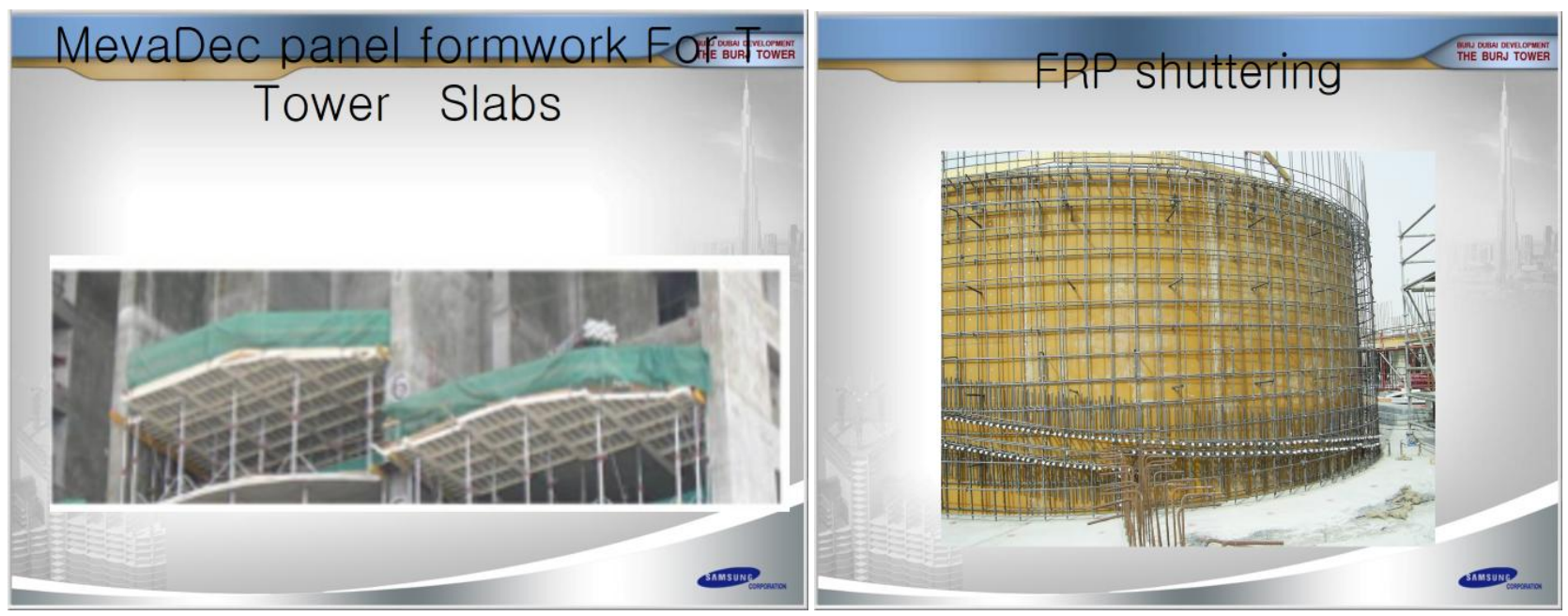

Fig-14: Tower Slab Formwork and FRP shuttering
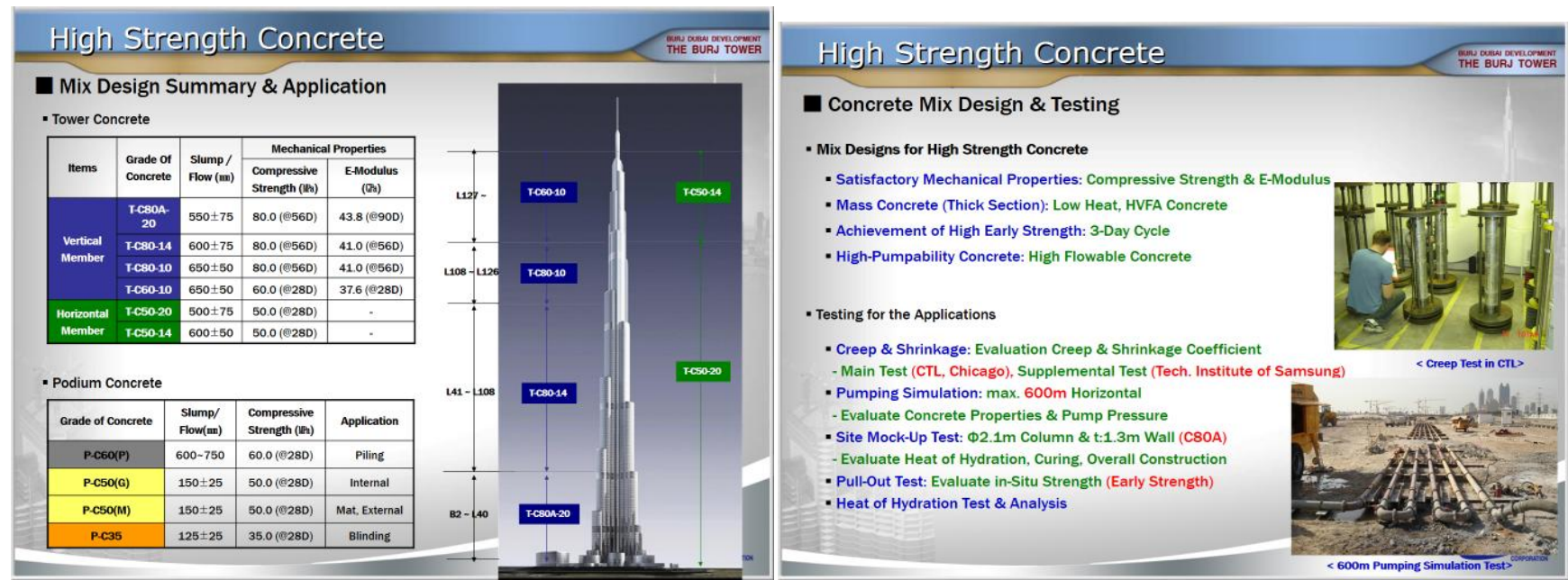

Fig- 15: Concrete Mix design Summary and Testing

\subsection{Concrete and Testing:}

High performance concrete C60 and C80 grade concrete was used for vertical members, and C50 grade concrete was used for horizontal members.

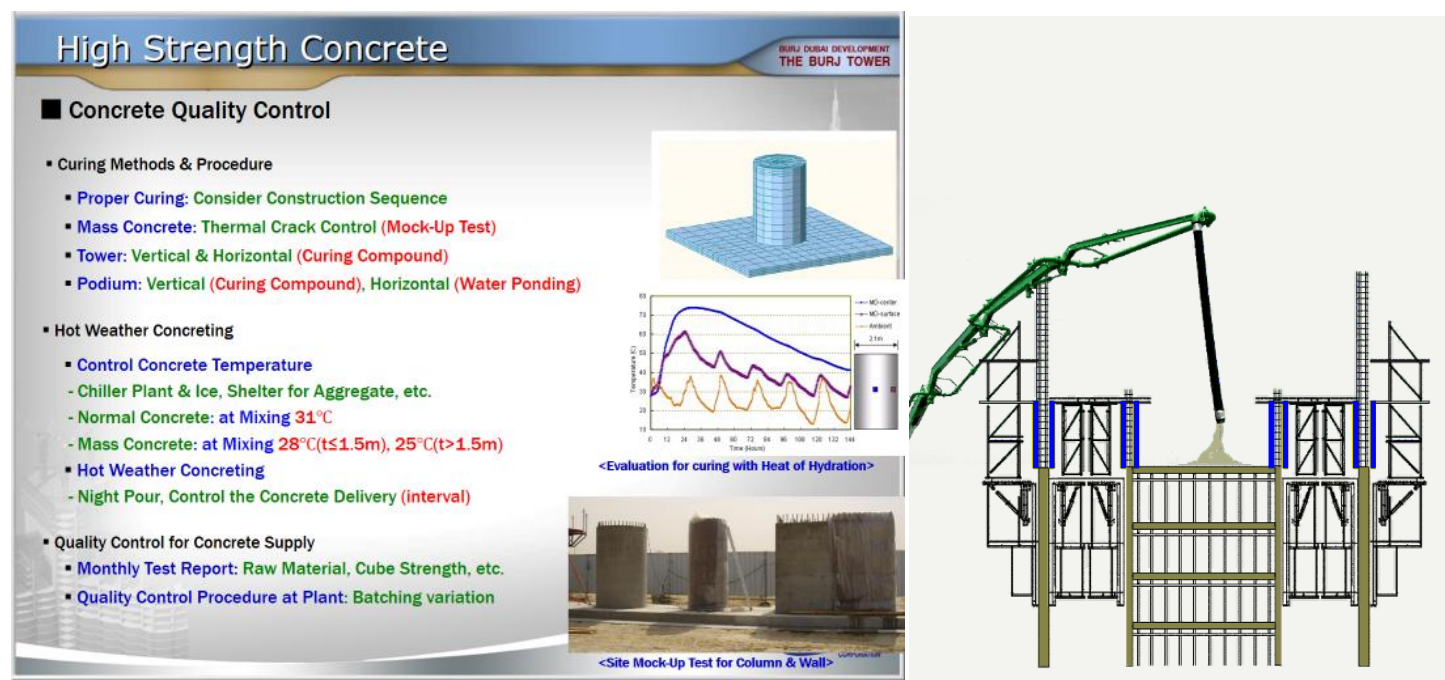

Fig-17: High Strength concrete Quality Control Testing and Pouring 

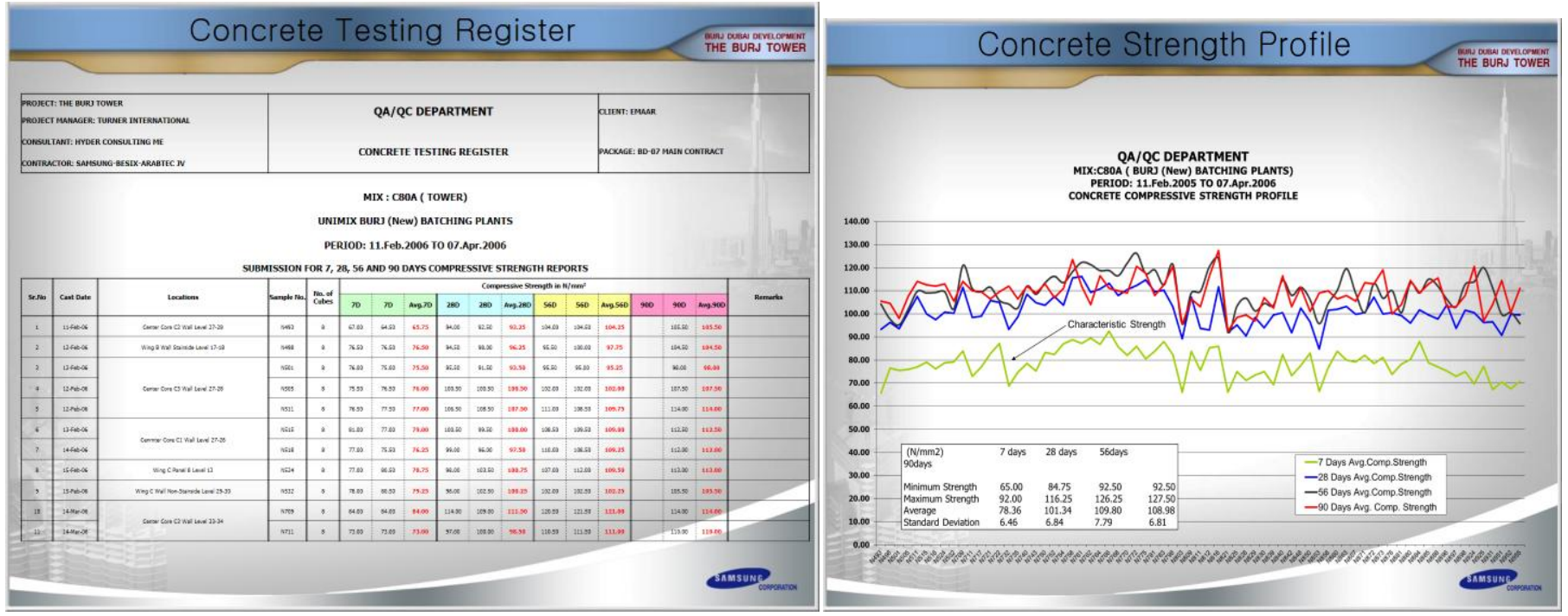

Fig- 18: High Strength concrete Testing Register and Strength Profile of Tower C80 Concrete

\subsection{Spire Erection Plan}
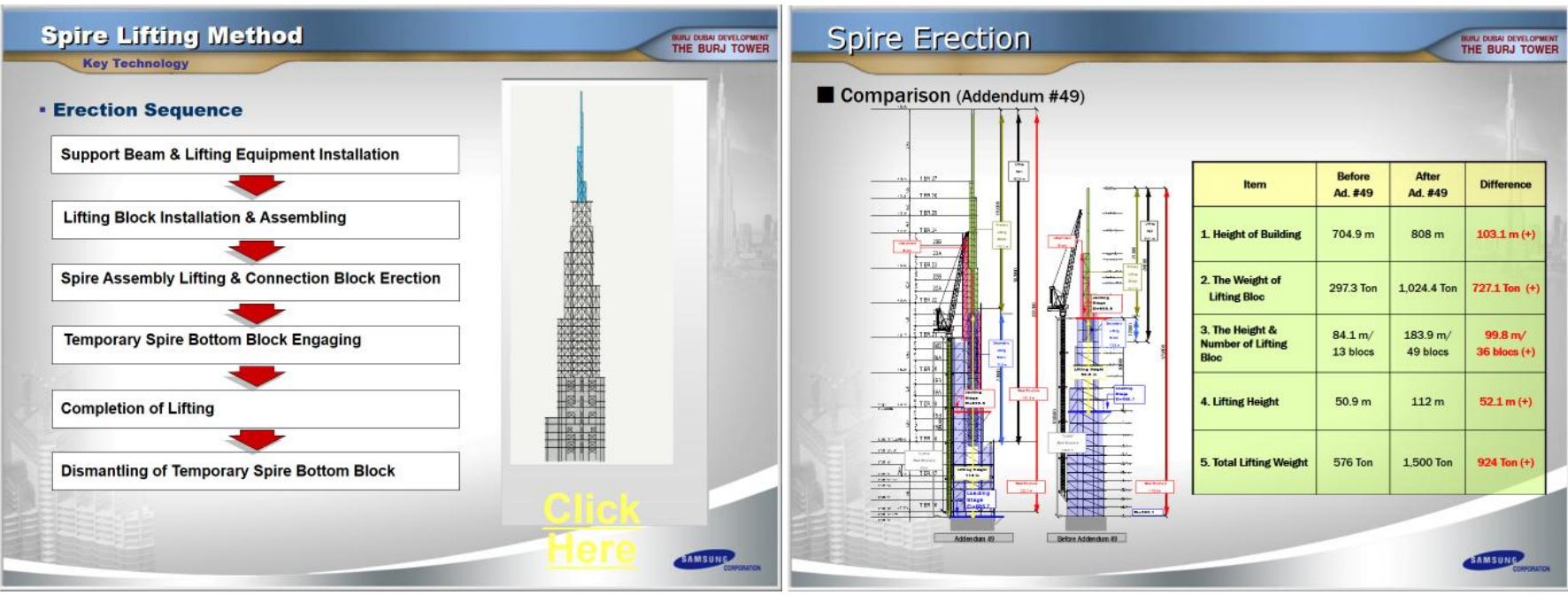

Fig- 19: Spire Installation sequence

\subsection{Building Movement Monitoring System}
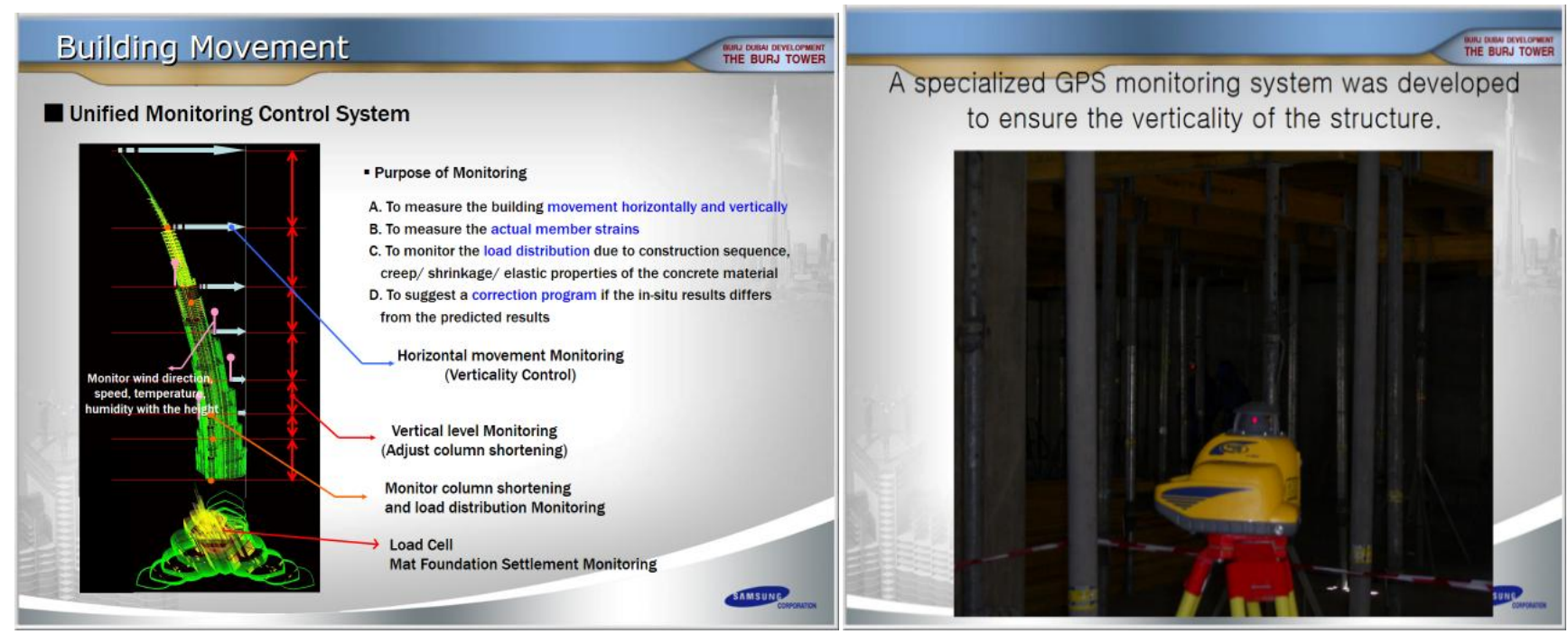

Fig- 20: Building Movement monitoring and Checking Verticality of Tower walls 


\section{CONSTRUCTION PHOTOGRAPHS}
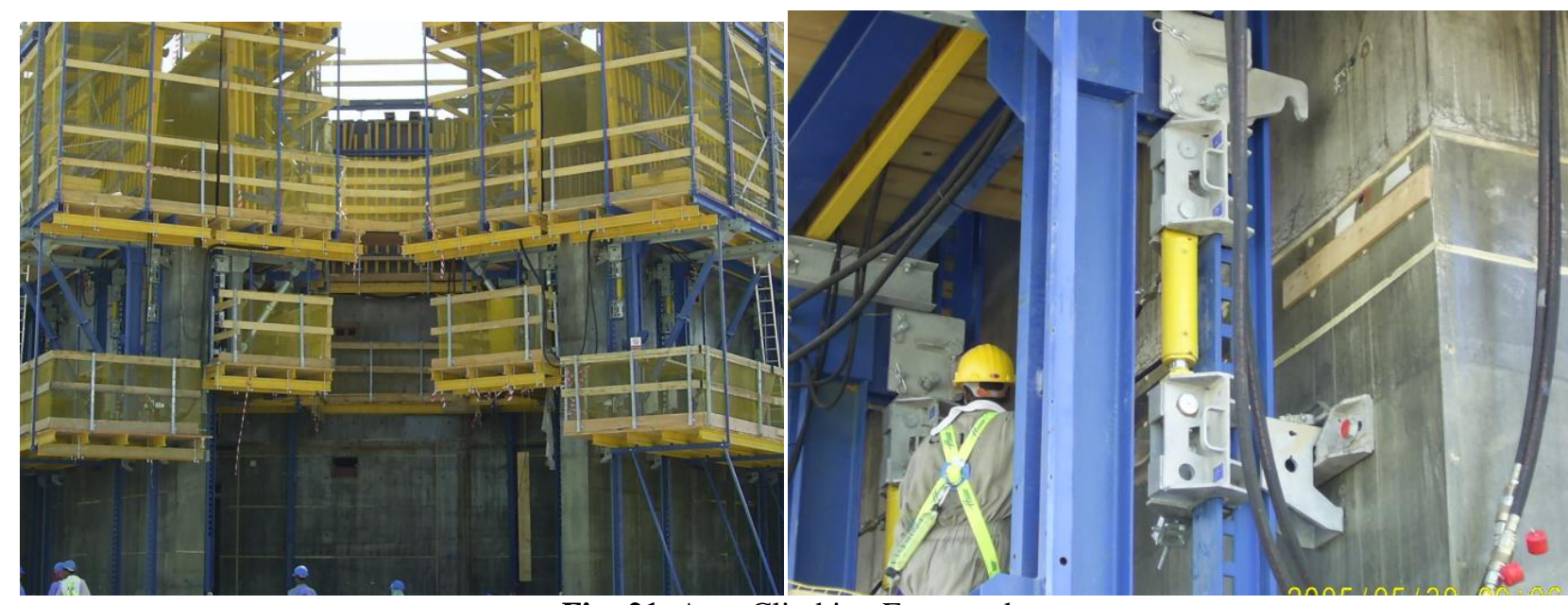

Fig- 21: Auto Climbing Formwork
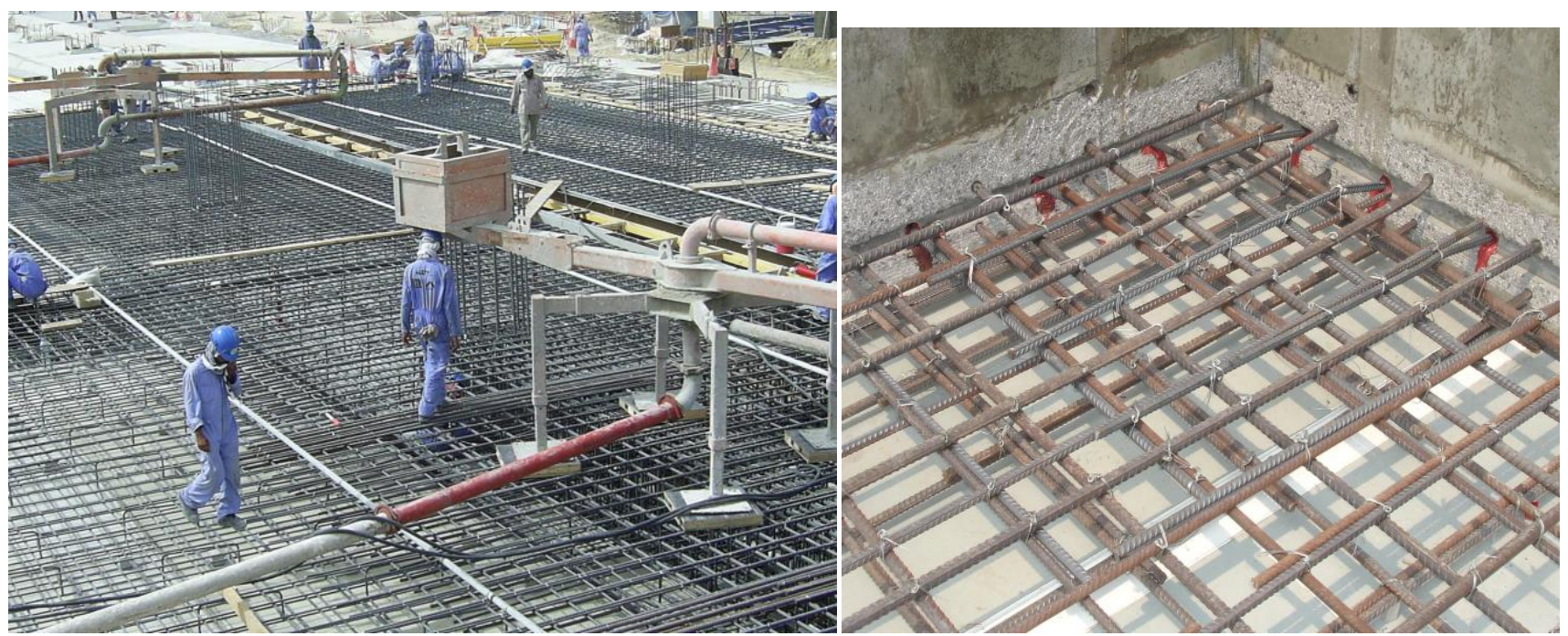

Fig- 22: Rebar: Mat Foundation and Tower Slab

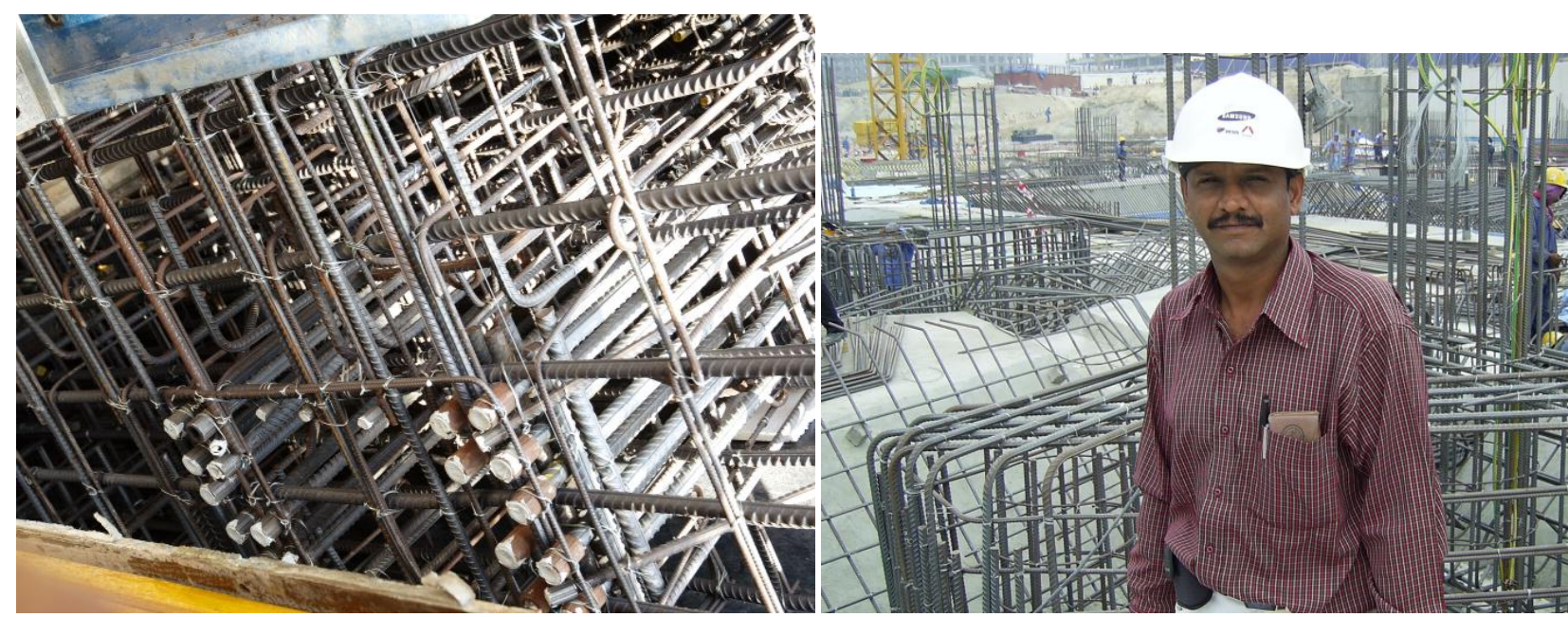

Fig- 23: QC Inspection: Mat Foundation and Tower Beam 


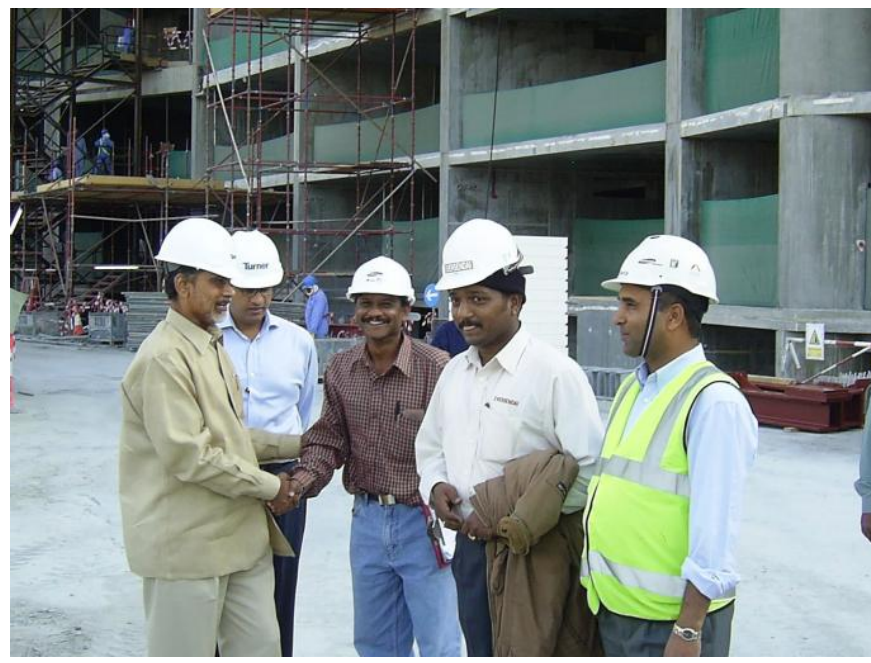

Fig- 24: Safety is a must for every one- PPEs and Safety induction to Visitors

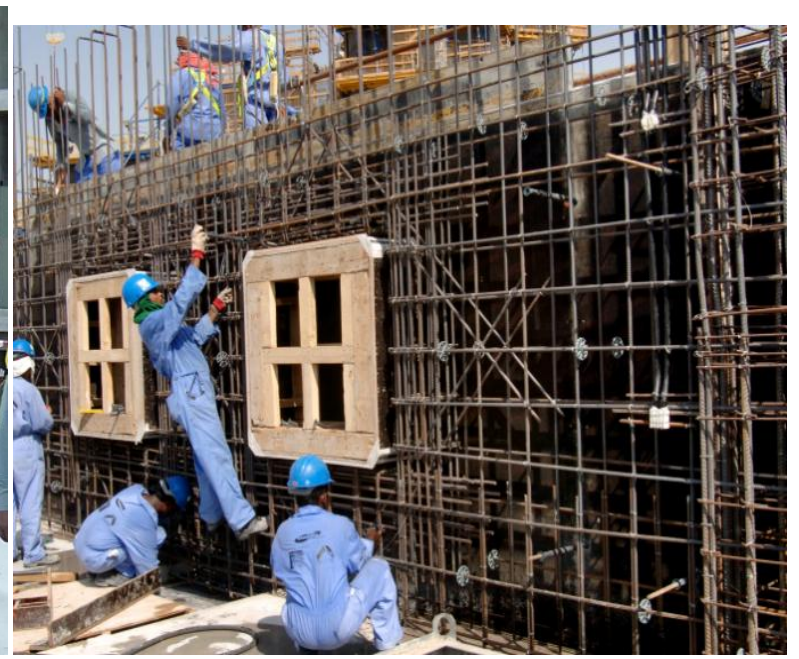

[6] Rajendra Prasad D.S, Kiran Kumar H R, Dattatreya J $\mathrm{K}$, Development of design software for the analysis of Tall Chimney, ICCIT, Mysore, June 2012.

[7] Rajendra Prasad D.S, Swaroop N , Dattatreya J K, Naveena.P.C , Selection of Pile Foundation Using Expert System and Design Using Visual Basic Programme For High Rise Building, International Engineering Post Graduate Research Conference ENGGPOS 2013 Technical program -2013, Feb 1-2, 2013, Coimbatore.

[8] Abdelrazaq, A, Kim, K. J., Kim, J.H. "Brief on the Construction Planning of the Burj Dubai Project, Dubai, UAE", 17tth IABSE Congress, Creating and Renewing Urban Structures - Tall Buildings, Bridges and Infrastructure, Chicago, September 17-19, 2008.

[9] Baker W, Pawlikowski J. Higher and higher: the evolution of the buttressed core. Civil Eng. 2012; 82(10): 58-65.

[10] Council on Tall Buildings and Urban Habitat. Tall Building Database. ctbuh.org.

\section{BIOGRAPHIES}

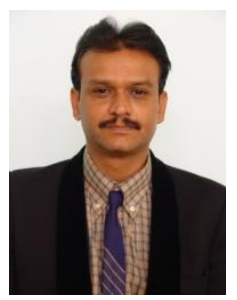

Dr. Rajendra Prasad D S is a Quality Head at Azemeel Contracting Company, one of the largest construction companyin the Kingdom of Saudi Arabia, thatcaters to Buildings, Infrastructures, Industrial and Refinery structures. Previously, Dr. Rajendra Prasad worked as a Chief Engineer-Qualityin BurjKhalifa TowerProject, Dubai with Samsung JV. $\mathrm{He}$ is a postgraduatein Civil engineering from UVCE, Bangaloreand having a Post-Doctoral degree in Civil Engineering. He is an author of more than 48 research papers and 21 books in various disciplines. 